\title{
Constructing Curricula: Rational choices around the use of simulations for optimal outcomes for students
}

\author{
Authors: \\ Margaret McMillan' · Mee Young Park² · Susie Yoon² \\ ${ }^{1}$ OAM Conjoint Professor, School of Nursing and Midwifery, University of Newcastle \\ ${ }^{2}$ Assistant Professor, School of Nursing, Cheju Halla University
}

\section{ABSTRACT}

Purpose: To highlight the value of using guidelines for determining the worth of learning events that center on simulations health profession practice.

Methods: Literature Review, Identification of principles to guide key faculty members around decision-making for optimal educational practices in the use of simulations.

Results: Collaborative practices in formative and summative curriculum evaluations involving academics lead to a better appreciation of the need for rational decisions at both the macro level (Course Design) and micro-level (implementation phase) of curriculum development.

Conclusion: Actual and simulated health professional practice provide numerous examples of situations that could be chosen to drive student learning. The selection of meaningful practice situations across the entire program needs to be based on agreed upon principles and criteria for selection. The latter need to reflect the conceptual framework of the curriculum. 


\section{BACKGROUND}

Countries across the world have a vision and mission to maintain standards for curriculum development in nursing, for example the National League for Nursing (2015). In Australia implications for governance and consistency in higher education are nested within the Tertiary Education Quality Standards for Accreditation (TEQSA) and the Australian Nursing and Midwifery Council (ANMC) standards center on outcomes around four design continua:

- Course organization

- Selection of learning experiences

- The actual learning process

- The assessment process

For programs reliant on Problem-based Learning (PBL) as a philosophy and methodology informing learning and teaching and curriculum design, there is a need to defend choices made at the macro-level construction of the curriculum. Macro-level curriculum development should focus on the outcomes of the entire program. Process oriented outcomes expressed as abilities are an important component of this: Critical thinking, teamwork participation and reflective practice. For both staff members and students, it is important that rational decisions are made about content and processes within all learning events (Conway \& Little, 2000).

Constructivism, such as that exemplified in processoriented curricula applicable to health professional education (Nyback, 2013), suggests that people construct knowledge and meaning from their experiences (perspectives, values, attitudes) and their understandings of these and apply these to the learning situation. It suggests that all learning takes places in a context. It has been argued that constructivism supports the education of health professionals by improving critical thinking skills to enable them to work with complex patients in a rapidly changing environment (Candela, Dalley, \& BenzelLindley, 2006; Park, Conway \& McMillan, 2016). Teaching within a constructivist framework requires educators to focus on learning outcomes - creating activities that cause students to make connections between facts and foster new understandings. Teachers then adapt their approaches according to student responses to encourage students to analyze, interpret, and predict information.

Therefore, the following principles inform design of curricula:

- It is the action context and the reality of practice that determines choices of learning situations

- Enquiry and processing skills mediate the learning so that information can be generated, not simply applied

- Given the focus on learning, not teaching, learnermanaged learning and self-direction in learning is a central feature of the student experience

- Clinical experience is integral to learning, that is, it is valid as initial stimuli for learning.

However, the belief that professional placement experiences lead to individualized learning around the demonstration of abilities described above, those that result in optimal and safe patient care, might not always be realized (Cockerham, 2015). Given that those abilities include some responsibility of the learner for their own learning and greater capacity for critical thinking, focussing on structured simulated learning events that hone these skills is desirable (Weatherspoon et al, 2015). The soundness of the curriculum blueprint and implementation plans and processes again become critical factors in determining successfullearning processes and outcomes for the students. 
We emphasise our central tenet that the choices in simulated and other learning events must reflect the conceptual framework of the curriculum and drivers for reform in the reality of practice: A range of clientele and practice settings must be represented if graduates are to appreciate the diversity and dynamism of practice, the complexity of the needs of their clientele and safety and quality concerns. Simulations must align to agree upon learning outcomes; hence the instructional design is central to success and must reflect decision-making, critical thinking and the application of knowledge and skills to client needs. Demonstration of efficiency and effectiveness of the students' thinking and action is as important consideration of the return on investment of the learning events themselves.

There are a number of contextual factors that influence curriculum implementation. These include:

- The level of agreement within the academic cohort on the need for a particular suite of choices around content and processes that align to the central tenets of the curriculum philosophy and methodology

- The level of commitment of faculty members to good governance of implementation decision-making and interrogation of outcomes

- The feasibility and practicality of the conceptual framework in a resource constrained higher education and health service environment

- The availability of guidelines to curriculum implementation for full, part-time and casual staff members

- The diversity within the student cohort and their contexts of learning in the contemporary on-line environment.

\section{SUGGESTIONS FOR CURRICULUM RENEWAL METHODOLOGY}

A literature review is typically undertaken as a first step in a curriculum renewal process (Waters, Rochester \& McMillan 2012). Faculty members should participate in a scoping study after agreement upon a conceptual framework such as an 'abilities-based approach' for their curriculum design. The scoping study involves scrutiny of all units (courses or subjects). To begin, a map of the major concepts in each Unit enables scrutiny of the entire curriculum for decisions on the best place for the introduction of concepts, the avoidance of repetition and the introduction of contemporary concepts that might emerge from the consumer movement, health service policy documents, international and national trends in professional development and novel ideas for curriculum renewal, especially those related to blended modes of delivery and the uptake of information technology. A second stage centres on the extent to which assessment items match the identification of the concepts introduced. This will be a test of the extent to which the academics actually value the concepts as major determinants of student ability, that is their confidence and competence in practice. Final deliberations centre on the best place and mechanism for learning activities, that is, as 'fixed resource' sessions or lectures, tutorial activities, simulated events or actual practice.

Given the complexities of contemporary health care we note that it is critical for educators themselves to reflect on both content and processes within the typical curriculum development journey and undertake:

- An appraisal of the contemporary contexts of practice (both acute and community) in partnership with service providers 
-A process to achieve consensus with service provider partners on beginning level practice

- Interrogation of data sets on student profiles and graduation statistics

- Benchmarking against statements of Graduate Attributes of a range of nursing curricula

- Identification of relevant trends, challenges and drivers from both the health and higher education sectors

- The potential for high levels of integration of information and communication technologies

- Realistic consideration of existing and future prospects for graduate employment

- Investigation of the potential for the use of additional clinical simulation as an adjunct to professional placements.

Through the use of a mapping exercise, Waters et al (2012) questioned the extent to which a thorough appraisal of changes in the discipline and curriculum context had been undertaken. Key academic personnel then engaged in a scoping study that enabled a though appraisal of the presentation and distribution of concepts throughout the program and the extent to which stated macro-level learning outcomes were tested through assessment tasks. Of particular importance was the interrogation of simulations and the return on investment for new initiatives. The following are principles that were a necessary to guide macro-curriculum decision making, including choices around the use of simulated learning events.

\section{PRINCIPLES AND GUIDELINES FOR USE OF SIMULATION}

In practice-base curricula integration of simulated events will be guided by:
- The accreditation standards set by the regulatory authorities. Aspirations for optimal learning outcomes will be realized with guidelines that assist in determining 'need and quality' issues, while implementation strategies will be further influenced by questions of 'feasibility and practicality', often impacted by resource (human and fiscal constraints);

- Decisions about 'what to choose' and 'how to organize' learning events centre on aspirations to provide students with meaningful links between a theoretical framework informing professional care and the actual performance of discrete activities. Students need guidance on the articulation of 'generalizable concepts' and 'particular application' in novel situations;

- A set of principles related the organization of the clinical practice component of the curriculum that assists curriculum implementers determine the suitability of learning methods reliant on blended modes of delivery (Lectures or fixed resource sessions, demonstration through face to face offerings or computer assisted learning, self-directed or learner-managed learning, integrated simulation activities, professional placement experiences).

Again we stress that health professional students engaged in laboratory simulations as learning activities should be able to acquire and apply knowledge to novel and changing situations. Therefore, the following principles apply to simulations that are consistent with sound educational design that is well grounded in theory as outlined by Nestel \& Bearman (2015):

- Design must be guided by 'agreed upon' educational goals and outcomes;

- Design must involve a mix of student interest goals and coherent goals for all; 
- The implementation plan must involve a variety of stimulus material and blended modes of delivery;

- The use of simulated clinical activities such as Objective Structured Clinical Assessments (OSCA) involve valuable tools but 'total immersion' in situations need to be avoided without appropriate reflection upon the processes and outcomes;

- Design must involve decisions around the mix of virtual and real components of the learning activity and the extent of complexity within the learning event;

- The level of complexity relates to the student need and the number of different activities within the learning event;

- Design is critical and must relate to meaningful outcomes for the student; Some challenges around 'conceptualization or abstraction' is highly desirable;

- Simulation that leads to a 'neat and tidy outcome' potentially misses deeper educational opportunities; reflection on the professional and personal learning is critical.

The ability of facilitators to create a reflective environment and manage student reactions and learning (and their own ability to think critically, problem solve and use and apply contemporary evidence) is critical to the success of process oriented learning events. Additional guidelines informing simulation will help refine judgments about the worthiness of particular learning events involving simulation that is well grounded in theory as outlined by Nestel \& Bearman (2015):

- Simulation is about transfer of meaningful concepts or the application of knowledge skills and attitudes relevant to practice in a structured learning environment
- Simulation in 'constructivist curricula' centres on 'learning about' and 'learning how' and understanding the learning process ie conceptualization, enquiry, selfdirection in learning

- Simulation about health care equates to the imitation of real world processes in the context of professional activities related to patient/client care

- Simulation is most useful when there is a need to provide a safe environment for 'structured learning events'

- In the simulated environment students learn about care activities that include complex situations from a range of disciplinary perspectives (health professional, bioscience, psych-social)

- Simulations should reflect levels of fidelity ie from simple tasks to exploration of a series of inter-related care activities

- Greater access to the 'virtual realm' should enhance the range of educational outcomes that can be addressed in simulations

- The measure of 'return on investment' relates to the extent to which sound educational goals are specified and aligned to measurable outcomes

- It is critical that assessment tasks include valid and reliable measurement criteria

- Activities included in simulation need to be complex enough to require more than that offered in a simple instruction book: The latter has its place in self directed learning activities

- The involvement of 'partly virtual' and 'partly real' activities/participants more accurately reflect the abilities required in the workplace 
- Use of activities arising from external sources, for example national initiatives and projects, need to reflect consideration of issues around context, culture and matters related to Intellectual Property.

Typical ongoing challenges for curriculum developers

The Guidelines developed by National Council of State Boards in Nursing www.ncsbn.org (NCSBN) remind curriculum developers that simulations are strategies not a technology that have the potential " to mirror, anticipate or amplify real situations with guided experiences in a fully iterative way". They note that principles should remain consistent, but the strategies offer the chance for some flexibility. The NCSBN highlight the following challenges in the uses of simulation:

- Initial and ongoing capital expenditure

- High financial costs

- Faculty development

- Ongoing faculty/administrative/technical support

The NCBSN caution that simulations are not real, that they often offer limited realistic human interactions. Further to this they note that the physiological symptoms might be underrepresented and that students may not take this type of learning event seriously.

\section{CONCLUSION}

Actual health professional practice provides numerous examples of situations that could be chosen to drive or enhance student learning. The selection of meaningful practice situations (actual and simulated) across the entire program needs to be based on agreed criteria. The selection criteria need to reflect the conceptual framework of the curriculum. Teaching within an enquiry and practice based framework such as PBL requires educators to focus on learning outcomes. There is a need to cause students to make connections between facts and link these within learning situations in order to foster new understandings. Teachers then adapt their approaches according to student responses to encourage students to analyze, interpret, and predict information. Strategies aimed to enhance student learning such as those offered within simulations should be critically reviewed using sound principles just as that demanded of any other component of the curriculum.

\section{REFERENCES}

Australian Nursing and Midwifery Council. (2018). Retireved from www.nursingmidwiferyboard.gov.au/

Candela, L., Dalley, K., \& Benzel-Lindley, J. (2006). A case for learning-centered curricula. Journal of Nurse Education, 45 (2), 59-66.

Cockerham, M. E. (2015). Effect of Faculty Training on Improving the Consistency of Student Assessment and Debriefing in Clinical Simulation., Clinical Simulation in Nursing, 11, 64-71.

International Nursing Association of Clinical Simulation and Learning. (2015). Retreived from http://www. nursingsimulation.org

Li, S. (2015). National Council of State Boards in Nursing The Role of simulation in Nursing Education: A Regulatory perspective. Retreived from https://ncsbn. org/Suling2.pdf

National Council of State Boards in Nursing. (n.d). Simulation Guidelines for Pre-licensure Nursing Education. Retrieved from https://www.ncsbn.org/16_ Simulation_Guidelines.pdf

National League for Nursing. (2015). NLN Vision Series: A Vision for Teaching with Simulation, USA 
Nestel, D. \& Bearman, M. (2015). Theory and SimulationBased Education: Definitions, World Views and Allications, Clinical Simulation in Nursing, 11, 349-354

Nyback, M. H. (2013). A constructivist approach to teaching and learning at the degree programme in nursing at Novia University of applied sciences. Retrieved from Finland: https://www.novia.fi/dmsdocument/29

Park, M. Y., Conway, J. and McMillan, M. (2016). Enhancing Critical Thinking through Simulation. Journal of Problem Based Learning, 3(1), 31-40.

The Department of Education and Training. (2016). Quality Indicators for Learning and Teaching (QILT) for students to access. Retrieved from https://www.qilt. edu.au/

The Australian Department of Education and Training. (2016). Education Services for Overseas Students legislative framework. Retrieved from https:// internationaleducation.gov.au/regulatory-information/ pages/regulatoryinformation.aspx

The Australian Tertiary Education Quality Standards (TEQSA).(2017). Higher Education Standards Framework 2015. Retrieved from http://www.teqsa.gov. $\mathrm{au} /$ regulatory-approach/higher-education-standardsframework

Waters, C. D., Rochester, S. F. \& McMillan, M. A. (2012), Driversfor renewal and reform of contemporarynursing curricula: A blueprint for change,. Contemporary Nurse, 41(2), 206-215.

Weatherspoon, D. L. Phillips, K. \& Wyatt, T. H. (2015). Effect of Electronic Interactive Simulation on Senior Bachelor of Science in Nursing Students' Critical Thinking and Clinical Judgment Skills. Clinical Simulation in Nursing. 11 (2), 126-133. 
